\title{
VIH y políticas preventivas en Chile. La importancia de la enunciación en la intervención desde Trabajo Social
}

\author{
Estefanía Vilches ${ }^{1}$
}

RESUMEN

El Virus de Inmunodeficiencia Humana se detectó en Chile en los años ochenta y solo en 2017 más de 6.000 chilenos fueron notificados como portadores (Ministerio de Salud, 2017). A pesar de los esfuerzos llevados a cabo, tanto por las entidades de gobierno como por las organizaciones de la sociedad civil, el porcentaje de personas viviendo con VIH o SIDA en Chile se ha mantenido creciente. Este aumento progresivo no ha logrado ser controlado por las políticas preventivas y sigue siendo un importante problema de la salud pública.

La propuesta argumentativa del presente artículo apela por modificar la enunciación para empoderar socialmente a los individuos que sufren agravio moral, buscando cambiar la atención de la intervención en el sujeto por la atención en el sistema, esperando así establecer una ruptura, en la que se observe y nombre de forma emancipadora desde el concepto autesiano de "déficit enunciativo". Lo que se busca construir desde la praxis en la lebenswelt colonizada por el ethos neoliberal, es la búsqueda por visibilizar relaciones de poder, dominación y opresión que reducen a la sociedad, posicionando así críticamente a la disciplina desde la lógica de la negatividad, para buscar un giro en la noción de intervención preventiva.

Palabras clave: enunciación, VIH-SIDA, teoría crítica, intervención preventiva

\section{HIV and Prevention Policies in Chile. The importance of enunciating intervention based on social work}

SUMMARY

Human Immunodeficiency Virus was detected in Chile during the 1980s, and in 2017 alone, more than 6,000 Chilean people were diagnosed as HIV positive (Ministry of Health, 2017). Despite efforts made by both government bodies and civil society organizations, the percentage of people living with HIV or AIDS in Chile has continued to rise. Preventive policies have failed

Chilena. Estudiante de Trabajo Social, Facultad de Ciencias Sociales de la Universidad de Chile.E-mail: estefania.vilches@ug.uchile.cl 
VIH y políticas preventivas en Chile. La importancia de la enunciación en la intervención desde Trabajo Social / Vilches

to stem this ongoing increase, which remains a significant public health problem.

This article puts forward an argument for modifying enunciation in order to socially empower individuals who are morally wronged, calling to shift attention from subject-based intervention to systemic action, thus seeking to establish a break point in that which is observed and named in an emancipatory manner, building on the Autesian concept of "enunciative deficit". The goal is to construct, using praxis in the lebenswelt colonized by the neoliberal ethos, a bid to shed light on relations of power, domination, and oppression that reduce society, thus critically positioning the discipline based on the logic of negativity, in search of a move towards the notion of preventive intervention.

Keywords: enunciation, HIV-AIDS, critical theory, preventive intervention.

\section{HIV e políticas preventivas no Chile. A importância da enunciação na intervenção desde o Serviço Social}

\section{RESUMO}

O Vírus da Imunodeficiência Humana (HIV) foi detectado no Chile nos anos 80 e somente em 2017 mais de 6.000 chilenos foram notificados como portadores (Ministério da Saúde, 2017). Apesar dos esforços realizados, tanto pelas entidades do governo como pelas organizações da sociedade civil, a porcentagem de pessoas vivendo com HIV ou AIDS no Chile continua crescendo. Este aumento progressivo não conseguiu ser controlado pelas políticas preventivas e segue sendo um importante problema de saúde pública.

A proposta argumentativa do presente artigo invoca a modificar a enunciação para empoderar socialmente os indivíduos que sofrem dano moral, buscando mudar a atenção da intervenção ao sujeito para a atenção ao sistema, esperando assim estabelecer uma ruptura, na qual se observe e nomeie de forma emancipadora desde o conceito de "déficit enunciativo" de Autès. O que se procura é construir desde a práxis na lebenswelt colonizada pelo ethos neoliberal é a busca por visibilizar relações de poder, dominação e opressão que reduzem a sociedade, posicionando assim criticamente a disciplina desde a lógica da negatividade, para buscar um giro na noção de intervenção preventiva.

Palavras-chave: enunciação, HIV-AIDS, teoria crítica, intervenção preventiva. 


\section{Introducción}

En la década de 1980 el régimen dictatorial de Augusto Pinochet implementó políticas económicas neoliberales que iniciaron un quiebre en el ámbito social, otorgándoles un carácter de segundo plano, reflejado en la disminución del gasto, inversión e intervención en las políticas públicas del Estado. El retorno a la democracia en 1990 conllevó una transformación en la esfera política y sociocultural del país, sufriendo modificaciones en relación con el rol de las políticas públicas hasta ese momento vistas en Chile. Si bien mantienen la línea neoliberal hasta la actualidad, han existido variaciones respecto a las formas en que es concebida la función del Estado respecto de las políticas públicas, que tienden a restituir derechos y políticas sociales, y en las que la noción de "pobreza", configurada desde una visión puramente económica, deriva hacia el concepto de "exclusión social" (Muñoz, 2018), que considera el ámbito político, social y cultural, tornando así un foco de políticas públicas para las mayorías excluidas, en el intento de amortiguar los efectos de la aplicación de estas políticas neoliberales en los años ochenta y noventa del siglo pasado.

Desde este escenario socioeconómico y su transversalización mediante el diseño de políticas públicas, es posible establecer ejes respecto del lineamiento de las intervenciones actuales, que favorecen la reducción del papel del Estado en ámbitos sociales. En términos concretos, el Estado se desliga de la responsabilidad social mediante la privatización y tercerización de los servicios sociales. El rol estatal se posiciona desde el fomento del individualismo, la competencia y la meritocracia propia del ethos neoliberal: "en el modelo estatal que se implanta a partir del nuevo siglo, la cuestión del neoliberalismo se juega fuertemente en que la responsabilidad de la gestión de la vulnerabilidad se transfiere a los individuos" (Rojas, 2018, p. 142).

El neoliberalismo, como generador de relaciones sociales contradictorias, no será excepcional con la disciplina de trabajo social y sus formas de pensar la intervención social. Si bien las políticas 
VIH y políticas preventivas en Chile. La importancia de la enunciación en la intervención desde Trabajo Social /Vilches

sociales deberían saber responder a las necesidades de transformación y redefinición de estrategias a la par de la evolución escenario social, este objetivo no se estaría logrando, ya que, como señalan Castro y Flotts (2018), se ve presente una baja reflexión respecto al teorizar crítico de la disciplina y el modo de intervenir.

Ante este contexto nacional es que surge la inquietud de repensar la enunciación colonizada de los programas sociales actuales, que poseen una carga enunciativa con el poder de construir nociones moralistas e inmóviles respecto de los sujetos y, con ello, reforzar la invisibilización social provocada por el agravio moral. Entenderemos "agravio moral" como la aflicción generada por las dinámicas de exclusión social, las cuales responsabilizan al sujeto por su condición; tal como señala Honneth: "estas contradicciones a menudo ya no son percibidas como contradicciones del capitalismo, porque los sujetos han 'aprendido' a responsabilizarse de su destino" (2009, p. 401).

Este agravio deriva en un desahucio social y cultural, que cobra pertinencia de analizar, ya que, frecuentemente, las intervenciones sociales podrían resultar insuficientes si no se logra comprender que las políticas preventivas deben estar conscientes de la pluralidad enunciativa existente y de la importancia de repensar cómo influir en las nociones colectivas. Ante esto, surge la importancia de pensar una construcción disciplinaria que considere específicamente aquellas nociones insertas en un contexto de incertidumbre para abordar la intervención de forma efectiva, ante la cual surge la necesidad de un discurso crítico y posibles vías de innovación ante los desafíos de la alta complejidad de los fenómenos sociales en el Trabajo Social.

El propósito del presente artículo es abordar la brecha enunciativa de la disciplina de Trabajo Social y su relación con las políticas públicas, entendidas como el desafío de desnaturalizar concepciones morales y otorgarles a las intervenciones una justificación epistemológica crítica, a partir del desafío nacional de reducir los contagios de VIH-SIDA en la población, mediante la revisión de 
la política pública preventiva existente desde el Estado. Este objetivo está desarrollado en cuatro ejes: primeramente, se realizará una contextualización respecto de los índices epidemiológicos de VIH-SIDA nacionales, para desarrollar el segundo eje, el marco conceptual titulado "Epistemología Frankfurtiana e intervención social", donde centraremos la mirada crítica sobre la necesidad de replantear la función del lenguaje y la enunciación en las políticas preventivas nacionales. La tercera parte del desarrollo, titulada "Cuando la prevención es moralista: El caso del déficit en prevención estatal del VIH en Chile", expondrá un análisis de la intervención prevención preventiva nacional de VIH. Finalmente, la conclusión incluirá una síntesis de lo examinado, plasmando los principales desafíos para la disciplina en torno a las intervenciones preventivas.

\section{Contexto epidemiológico y el desafío enunciativo}

El VIH pertenece a la familia retrovirus, de la subfamilia lentivirus; su principal característica es impedir a las células llevar a cabo sus funciones naturales, debilitando en forma progresiva el sistema inmunitario del ser humano, destruyendo su capacidad para combatir la infecciones y enfermedades. El SIDA, en cambio, es descrito y enunciado como una enfermedad letal, causada por el VIH, el cual destruye el sistema inmunitario desprotegiendo al organismo de las enfermedades que normalmente no serían mortales. Esta insuficiencia corrobora el diagnóstico de SIDA, que corresponde a la fase de inmunodeficiencia si se mantiene la historia natural de la infección sin tratamiento antirretroviral (ONUSIDA, 2007).

En Chile, la epidemia de este virus se ha caracterizado por el sostenido aumento de la detección de portadores, existiendo una proyección nacional de entre 70.000 a 100.000 casos, mientras que de esta estimación, 46.924 personas fueron confirmadas el año 2017. Estos no necesariamente podrían ser señalados como un exclusivo aumento de contagios, sino también como un incremento paralelo de la preocupación de las políticas públicas, pri- 
VIH y políticas preventivas en Chile. La importancia de la enunciación en la intervención desde Trabajo Social / Vilches

vadas y ONG respecto del virus, manifestada en el aumento del monitoreo desde los centros de la red de salud y la realización de una mayor cantidad de exámenes (MINSAL, 2018).

Más allá de los datos, "la existencia del VIH-SIDA no constituye únicamente un problema epidemiológico, político o económico sino también social" (Labra, 2011, p. 42). Debido a la concepción fatalista que se tiene del virus y a la construcción de estereotipos que conllevan dinámicas de agravio moral, junto con la brecha de información existente respecto al contagio, etapas y su tratamiento, se evidencia la dificultad en la tarea de prevenir; por ende, la importancia de realizar una separación entre la concepción de VIH y SIDA radica en el foco de la enunciación y las nociones que la comunidad posee respecto del virus y el síndrome, debido a que existe el riesgo de generalizar la portación de este virus con el riesgo de mortalidad.

\section{Epistemología frankfurtiana e intervención social: sobre el agravio moral}

El trabajo social contemporáneo, desde el enfoque crítico de la Escuela de Frankfurt, propone la importancia de la hermenéutica como una corriente filosófica útil para explicar las sociedades capitalistas avanzadas, para intervenir en busca de la liberación de los individuos con miras hacia su horizonte normativo: la transformación social, mediante una perspectiva crítica de las estructuras y del contexto en el que se centra la intervención en pro de la emancipación de los individuos.

Ante el capitalismo reificado, la teoría frankfurtiana postula la necesidad de experimentar la colonización del mundo de la vida, para comprender el agravio moral desde la vivencia y sus paradojas, "la reificación se torna inequívocamente asimétrica en las relaciones entre la malla de integración sistémica y la reducción de la integración social. Así, el capitalismo se muestra reificado, pero al precio de un olvido" (Matus, 2017, p. 78). Ante este olvido, emanado de la pérdida de noción de una sociedad colonizada por 
el ethos neoliberal, surge la necesidad de enfrentar el conocer mediante la negación frankfurtiana.

La epistemología de la teoría crítica está compuesta por la dialéctica negativa, que asume a los objetos como una totalidad de características, mucho más que su concepto, puesto que el estado de concepto en sí mismo es una cosificación que le aísla de la totalidad. Ante esta afirmación, Adorno señala que "hay que renunciar a la ilusión de que la esencia pueda ser constreñida a entrar en la finitud de las determinaciones filosóficas" (2004, p. 21), configurándose así la constelación, que busca la superación de la naturalización impuesta normativamente como medio de opresión. Posteriormente el momento de la ruina configura la conciencia del carácter móvil del conocer y finalmente emerge el momento de la memoria, en el cual se logra la dimensión de la protección de las impresiones sobre el riesgo del deterioro del recuerdo. El sentir indignación por este capitalismo reificado y la colonización del ethos neoliberal, desde esta forma de conocer examinando las ruinas de pasado, para así rearticular la memoria, permitirá configurar una crítica emancipadora capaz de generar constelaciones de intervención que posibilitan la emancipación, ante las relaciones de dominación que se esconden en la sociedad.

El teorizar crítico de la disciplina, al articularse con la intervención social y la vinculación con el medio, requiere las herramientas necesarias para actuar frente al nivel de complejidad del capitalismo reificado, por ende, el desarrollo de constelaciones como dimensiones del conocer, capaces de apelar por la transformación social, primeramente vuelve necesario repensar el dualismo entre teoría y práctica.

El empirismo, "puede ser penoso para quien lucha más, rara vez, lo conduce a la desesperanza, porque además el sujeto sólo puede experimentarse a sí mismo al final de sus vagabundeos" (Benjamin, 1996 citado en Matus, 2010, p. 24), es decir, es solo por medio de su experiencia que logra obtener conocimiento. Sin embargo, se considera que esta noción limita las potencialidades del 
VIH y políticas preventivas en Chile. La importancia de la enunciación en la intervención desde Trabajo Social / Vilches

Trabajo Social, ya que no solo debe observar una realidad para la mera obtención de datos desde la experiencia en un contexto social determinado. Mientras que la hermenéutica frankfurtiana es considerada como una herramienta de análisis y visibilización de la construcción de subjetividades, esta desarrolla las herramientas para cuestionar, ya que "cuando el concepto de experiencia es degradado, manipulado, extorsionado, se pierde un valor central, el valor de hacer otras preguntas" (Matus, 2010, p. 25). Esta degradación se materializa en las limitaciones conceptuales y filosóficas que no permitirían conocer más allá de lo vivido.

La formación de los profesionales de Trabajo Social en Chile posee características que reducen a éste a la implementación de metodologías de intervención, pensadas en torno a una separación entre el empirismo y la hermenéutica. La praxis en Trabajo Social ha sido entendida como una alejada de su reflexión sobre su quehacer, relegando un rol central en la intervención, sin cuestionar los fundamentos teóricos que sustentan el análisis de la realidad o contexto en el que se pone atención. Frente al dualismo planteado ante la praxis y los conocimientos hermenéuticos de la formación profesional que ofrecen las instituciones educativas, surge el empobrecimiento de la enunciación y crítica disciplinar, ya que al desplazar la hermenéutica como corriente de pensamiento y reflexión, el trabajado social reduciría sus herramientas para realizar intervenciones eficientes, ya que este "no puede quedar instaurado sólo a un nivel testimonial" (Matus, 2010 p. 21).

La hermenéutica permite comprender las relaciones sociales en una totalidad mediante la consideración de los relatos que dan cuenta de las construcciones de las subjetividades, ante las cuales su vinculación intrínseca con la praxis, pareciera ser casi imprescindible para enfrentar esta carencia de articulación entre el teorizar crítico y la praxis:

Debería crearse, entonces, una conciencia de teoría y praxis que no las separara de un modo arbitrario ni destruyera la teoría 
mediante el primado de la razón práctica, ya que, pensar es un hacer y la teoría es una forma de praxis. (Matus, 2010, p. 21)

Lograr construir un equilibrio entre formación empírica y hermenéutica para afrontar la complejidad social, analizando las contradicciones sociales e interviniéndole, posibilitará el ejercicio consciente de la colonización del lenguaje, ya que "la manera en que un fenómeno social es comprendido, ya sea explícita o implícitamente, permite la justificación, problematización u omisión de ciertas decisiones y acciones profesionales" (Garrett, 2013 citado en Muñoz, 2018, pp. 262-263).

La intervención social comienza con una lectura del mundo desde una perspectiva centralizadora de la sociedad, mediante la que se propone el concepto de "déficit enunciativo" para explicar lo existente, tal como señala Michel Autés: "el acceso a la palabra, a la capacidad de enunciación, produce la existencia social en tanto que ella abre al mismo tiempo una capacidad de acción en el mundo social" (2005, p. 245). La carencia de una formación hermenéutica en Trabajo Social, construye este abanico lingüístico, limitándole a explicar con las herramientas que la formación de los profesionales entrega, no permitiendo una mirada profunda en la intervención social. Esta mirada crítica de los recursos lingüísticos del Trabajo Social propone, en otras palabras, un acto de visibilización y reconocimiento de los individuos que genera herramientas para su empoderamiento, gestionando el abanico de oportunidades para que estos individuos y colectivos puedan ejercer sus competencias dentro de la sociedad. "El Trabajo Social tiene que ver con la subjetividad, que tiene que ver con la capacidad de enunciación del sujeto" (Autes, 1999, p. 246).

Intervenir por el mero acto de acercarse a una realidad o complejo social, desde la distancia del dualismo entre el empirismo y la hermenéutica, reduce el rol de los trabajadores sociales a uno que no devela las tensiones que existen entre aquellos sujetos que configuran dicha realidad. Es decir, esta carencia filosófica, desde la comprensión de los procesos sociales y sus dinámicas manifesta- 
VIH y políticas preventivas en Chile. La importancia de la enunciación en la intervención desde Trabajo Social / Vilches

das en las relaciones que se dan entre los sujetos, tiende a normalizar las situaciones intervenidas, teniendo como resultado la negación epistémica que deriva en una forma de conocer limitada.

Bajo este análisis, se expresa una visión que apela a generar herramientas políticas y sociales desde la formación de actores sociales que modifiquen estos errores de enunciación, para empoderar socialmente a los individuos que sufren este agravio moral sin centrarse en el sujeto, ya que, a diferencia de otros enfoques, se observa y critica desde una lógica de la negatividad, que da un giro en la noción de emancipación.

Si se piensa la intervención desde el enfoque crítico de la Escuela de Frankfurt, la enunciación y el lenguaje se tornan claves para la emancipación, ya que al observar y nombrar de forma emancipatoria las dinámicas sociales y los sujetos que les configuran, también lo es la praxis. De este modo, se busca construir en la lebenswelt colonizada de la sociedad capitalista, que establece relaciones de poder, dominación y opresión, que invisibilizan y reducen a la sociedad, ante la cual la función del lenguaje debe estar:

Al servicio de la coordinación social, salvando las barreras culturales y las creencias individuales o de grupos. Al conectar el concepto de lenguaje con el de sociedad, y este con el de mundo de la vida como su horizonte contextualizador, se abre la posibilidad de una teoría del lenguaje que concilie la acción con la interpretación. (Fernández, 1997, p. 30)

A este respecto, Habermas propone su Teoría de la Acción Comunicativa (1981) para el conocimiento de las formas de construcción de la realidad social y como el elemento motor que posibilitará cualquier acción conducente a la autoemancipación de los individuos frente a los sistemas de dominación. El lenguaje es acción e interpretación, manifestado como componente de la reflexión crítica en la que se ejerce una anticipación utópica, ya que cualquier sociedad futura regida por la razón deberá ser mediatizada por los autores por formas comunicativas y culturales libres, ajenas al control social y portadoras de un consenso. Hacia ese ob- 
jetivo, que es la democratización de formas comunicativas igualitarias y libres, se orientan las contribuciones de la Teoría Crítica a una Teoría de la Comunicación de carácter anticipatorio y emancipador. En este sentido, para Habermas, toda liberación depende de la toma de conciencia, y el surgimiento de esta se ve estorbado siempre por el predominio de necesidades y satisfacciones que se han convertido en propias del individuo. Es decir, las necesidades de la vida real apremian a tal punto que no permiten que los sujetos sean conscientes de la real dimensión de estas necesidades, que además nacen desde la naturalización de las manifestaciones del ethos neoliberal.

\section{Cuando la prevención es moralista: el caso del déficit en prevención estatal del VIH en Chile}

Las construcciones lingüísticas emanadas de las intervenciones sociales y las políticas públicas, sesgadas de una mirada hermenéutica y crítica de la realidad de las personas portadoras del VIH y aquellas diagnosticadas de SIDA, han contribuido a normalizar la percepción de estos como de sujetos desprovistos de derechos, ya sea por la radicalidad con la que se ha descrito esta enfermedad en el imaginario social, o bien por la estigmatización y posterior discriminación de los inmunodeficientes. Esta realidad ha sido construida desde la marginación y discriminación de estos sujetos de derecho empobrecidos y empobrecidas, ya que esta enfermedad ha sido caracterizada como una que afecta a cierto sector o grupo de la sociedad. Ello ha derivado en lo que hemos definido como "desahucio social", pues una vez diagnosticados en la red asistencial son tratados como portadores de una enfermedad terminal, inclusive antes de declarárseles el SIDA. Además, de no entregarse las garantías estatales de tratamiento, acompañamiento y monitoreo a los portadores, el sistema no posee información que los caracterice más allá de su sexo biológico y orientación sexual, como es por ejemplo la tipificación de sus condiciones socioeconómicas. Es decir, existe un vacío en la información sobre estas personas desde el Estado chileno, que deriva entonces en la vio- 
VIH y políticas preventivas en Chile. La importancia de la enunciación en la intervención desde Trabajo Social /Vilches

lación de sus derechos humanos a la salud y en su dignidad como personas humanas.

Según el artículo 12 del Pacto Internacional de Derechos Económicos Sociales y Culturales, firmado por Chile en 1976, los Estados partícipes se comprometen a proteger el derecho de toda persona al disfrute del más alto nivel posible de salud física y mental, para "la prevención y el tratamiento de las enfermedades epidémicas, endémicas (...) y la lucha contra ellas" (INDH, 1972, p. 10). Sin embargo, el programa nacional de prevención de contagios de VIH 2017-2018 posee un enfoque colonizado por el discurso moral, y con ello la construcción social de estereotipos, ya sea en sus eslóganes o en los mensajes no verbales que intentan transmitir en las campañas, o mediante símbolos y modelos. La importancia de esto radica en el mensaje fatalista que propone "salvar la vida". A continuación, describiremos el plan en dos estrategias principales: comportamentales y estructurales.

Respecto de las estrategias comportamentales, existe el eje de consejería dentro de los servicios de prueba de VIH, implementados para vincularse de forma paralela con la educación y comunicación en población clave, teniendo como objetivo principal adolescentes y jóvenes, hombres y mujeres, de entre 15 a 29 años (MINSAL, 2017).

Este acceso a información sería permitido por las redes sociales y medios de comunicación de frecuente acceso. Mientras que la estrategia estructural está pensada para integrar los diversos servicios de salud de forma coordinada, así como la realización de reformas políticas y legales, fomento del apoyo social, con enfoque de determinantes sociales y el empoderamiento y participación comunitaria, la promoción de equidad de género y diversidad, DDHH e interculturalidad. Esperando con esto eliminar el estigma y la discriminación de los sujetos portadores.

La transversalidad del proyecto preventivo pareciera considerar las principales aristas sociales para enfrentar el desafío de reducir los contagios; sin embargo, el déficit enunciativo existente en el 
programa conlleva repercusiones respecto al objetivo de reducir los contagios, ya que primeramente se percibe el desafío de forma deshistorizada e individualizada, derivando en la construcción de los perfiles a intervenir basados en estereotipos, afectando las dimensiones de difusión y de educación que se ven influenciadas por esta noción moralista:

Las actuales configuraciones de lo social se evidencian en diversas categorías que dan lugar a lo que se ha denominado una cierta opacidad de lo social. Esta contiene, por sí misma, un desafío de indagación que involucra, al menos, tres requisitos: una exigencia de historicidad, una inconformidad con los sistemas simplistas de interpretación y el observar la interpretación entre las lecturas y formas de interpretar lo social con las mudanzas existentes dentro de lo social. (Matus, 2003, p. 58)

La comprensión de la dimensión histórica es necesaria para poseer las herramientas hermenéuticas orientadas hacia una buena interpretación que permita la comunicación. La deshistorización de los fenómenos sociales, entendida como el desentendimiento de los antecedentes históricos de la temática a analizar, desconoce las deudas pendientes del pasado (Matus, 2017), desliga la intervención de su contexto y, con ello, también impide generar una crítica transversal al sistema. Reduciendo las posibilidades de referirnos y comprender los fenómenos sociales, debido a la naturalización que genera el pensar desde una brecha contextual generando una reducción de la crítica.

Desde esta misma línea, la dimensión de caracterización de los sujetos a intervenir en una política preventiva debe estar consciente del riesgo de reproducir lógicas exclusionarias, ya que al construir un perfil objetivo, que está principalmente centrado en la diferenciación de un sujeto en torno a las deficiencias o carencias que posee para generar un cambio, existe la posibilidad paradójica de alejar el objetivo de intervención y producir rechazo social debido al lenguaje utilizado para enunciar al sujeto. Por ello, estar consciente que "los actos del Trabajo Social no sólo tienen el lenguaje 
VIH y políticas preventivas en Chile. La importancia de la enunciación en la intervención desde Trabajo Social /Vilches

como herramienta, sino que el Trabajo Social está inscrito en el lenguaje" (Autès, 1999, p. 238), es imprescindible para construir una perspectiva crítica de las intervenciones preventivas.

La importancia de analizar el impacto de los conceptos predominantes en las intervenciones ortodoxas, utilizados para referirse a fenómenos sociales o sujetos, radica en evaluar si un cambio de estas categorías y conceptos abre nuevas posibilidades de entendimiento:

La cuestión acá es que "el otro" puede contingentemente adoptar las características dada por quien lo mira y busca nombrar. Y si bien a un otro, subordinado, jerarquizado, se le puede conceder alguna virtud estética o moral, muy difícilmente se le otorgará un estatuto de legítimo pensamiento. Asimismo, desde esta expresión de un régimen de la mirada sobre el otro, se construyen una serie de imaginarios socioculturales. (Matus, 2003, p. 61)

La intervención preventiva sitúa tres perfiles clave a intervenir en su campaña comunicacional 2017: jóvenes, mujeres trabajadoras sexuales y homosexuales; sin embargo, es interesante considerar que, de acuerdo con el MINSAL, el principal grupo etario afectado son hombres entre 20 a 49 años (2017). Esto podría ser explicado debido a la construcción de perfiles basados en prejuicios y proyecciones estadísticas, realizadas en torno a estereotipos que estigmatizan y discriminan a los portadores de VIH.

Este fenómeno social es frecuente por sabérseles o suponérseles infectados por el virus, y el temor construido de un posible contagio tan solo al tomar contacto con un portador o una portadora. Esta esta triple afección -estereotipación, estigmatización y discriminación- provoca un desahucio social y des-reconocimiento de derechos, situación que traba su acceso al tratamiento y afecta la relación con su entorno social; por ejemplo, acceder a un empleo o la vivienda entre otros derechos. Estas afecciones contribuyen al rechazo social ante dialogar sobre la significación que posee 
el vivir con el virus y recibir tratamiento antirretroviral, pues "este estigma y la discriminación vinculados con el VIH desalientan a las personas infectadas y afectadas (...) [a] recurrir a los servicios sanitarios y sociales" (ONUSIDA, 2018).

Los imaginarios socioculturales conllevan que quienes necesiten acceder a información, educación y apoyo sobre el virus desarrollen aversión a vincularse a estos servicios que están accesibles a la comunidad. Para modificar estos imaginarios socioculturales, con el fin de generar una prevención consciente del agravio moral existente en torno al VIH-SIDA, recae el desafío preventivo en la dimensión educativa, debido a la importancia del uso del lenguaje, las interpretaciones y las reproducciones de estas construcciones sociales.

La intervención nacional está centrada en un fuerte énfasis individual, en el cual se invita a las personas a cuidar sus propias vidas por medio de la realización del examen y el uso de condón; sin embargo, no existe información respecto de lo que significa ser portador del virus, la realización del tratamiento y la posibilidad de asumir un rol preventivo y de cuidado con el entorno y las próximas parejas sexuales al realizar el tratamiento retroviral y tornarse indetectable, lo que deriva en la ausencia de control desde las instituciones.

El fatalismo de la campaña del MINSAL 2017-2018 bajo el eslogan: "Salva tu vida y la de los demás" puede resultar contradictorio, debido a que realiza un llamado a sentir temor por ser portador, provocando un rechazo social generalizado hacia la vinculación con la temática: "cualquier acercamiento a la realidad viene mediado por prejuicios, expectativas y presupuestos recibidos, procedentes de la tradición y que determinan, orientan y limitan la comprensión" (Cordero-Ramos, 2011, p. 94). La responsabilidad de generar una recepción positiva del mensaje es principalmente estatal, ya que la intervención preventiva debe provocar una interpretación que genere empatía e inquietud por aprender y ser agente activo: 
VIH y políticas preventivas en Chile. La importancia de la enunciación en la intervención desde Trabajo Social / Vilches

Las políticas públicas y sociales, no se pueden nombrar unívocamente: todas requieren un acto de interpretación. No hacerlo y pensar en intervenir como si esto fuese una línea directa es una arbitrariedad. Además, desde un acto de aplicación mecánico es muy difícil ver y abrirse enriquecedoramente a contemplar otros discursos. (Matus, 2003, p. 59)

\section{Reflexiones}

Política e ideológicamente, el modelo neoliberal ha construido un modo de pensar e intervenir sobre lo social que constituye un reto para el pensamiento crítico contemporáneo: el desafío de innovar en la intervención, desde el cual las tensiones disciplinares respecto a diversos enfoques se verán en la palestra de la discusión, mediante la tarea de identificar estos aspectos críticos en los procesos que permitirán emerger posibilidades de innovación, darán carácter a la experiencia del Trabajo Social.

La vinculación de la disciplina con el enfoque teórico frankfurtiano, considera la noción epistemológica y hermenéutica como el proceso y producto de una construcción histórica que puede ser transformadora desde sí misma, capaz de evaluar su carga histórica y reconocer las demandas que subyacen en la dinámica de lo social y en la memoria colectiva. "El proceso de intervención da cuenta de una forma de ver el mundo y de imaginar los horizontes posibles de transformación, es decir, supone un lugar de enunciación" (Muñoz, 2018, p. 263). Respecto de la influencia de la colonización del ethos neoliberal en la disciplina, que incide en la capacidad de cuestionar y criticar las dinámicas reproductivas de exclusión, des-reconocimiento y deshistorización de los fenómenos sociales, deriva en una reducción de las problemáticas sociales y la injusticia de la oferta y demanda de los sistemas, culpabilizando o personificando esta culpa en quienes se han visto excluidos o marginados, como es en la construcción de estereotipos y discursos moralizantes sobre las personas portadoras de VIH-SIDA. 
La necesidad de generar los espacios de discusión y retroalimentación de la intervención permitiría dar consistencia de las perspectivas adoptadas y aplicadas en la práctica, que, como señala Muñoz (2018), también permitirá imaginar posibilidades para la transformación del orden hegemónico social. Para contrarrestar la lógica neoliberal de la política social, desde una perspectiva reflexiva y transformadora, urge centrar la atención en la complejidad social, las demandas de esta, la colonización del mundo de la vida y la invisibilización de las contradicciones neoliberalistas mediante prácticas colectivas de crítica, retroalimentación de la intervención y mejoramiento de la formación profesional.

Una mirada de la sociedad, desde la reflexión crítica, otorgaría al Trabajo Social las herramientas necesarias para evidenciar aquellas contradicciones que emergen desde la política pública. Para el caso de la salud, como un derecho de todos y de todas, respecto a la campaña de prevención del VIH-SIDA 2017-2018, se evidencia una contradicción enunciativa, en tanto esta indica "Salva tu vida y la de los demás", mientras que la connotación fatalista conduce esas vidas hacia el desahucio social, marginando a quienes porten el virus y a quienes ya se les ha declarado la enfermedad. Lo anterior evidencia que "una contradicción es paradójica cuando precisamente con la realización que se intenta de tal propósito se reduce la probabilidad de realizarlo" (Giddens, 1995, citada en Honneth, 2009, p. 401).

\section{Bibliografía}

Adorno, T. W. (2004). Dialéctica Negativa: La jerga de la autenticidad. Madrid, España: Editorial Taurus.

Autes, M. (1999). Les Paradoxes du Travail Social. París: Editions Dunond.

Castro-Serrano, B. \& Flotts, M. (2018). ¿Transformación social sin cambio? Puntualizaciones para un nuevo imaginario del trabajo social, en M. Flotts y B. Castro (Eds.), Imaginarios de transformación: el trabajo social revisitado (pp. 21-46). Santiago de Chile: RIL Editores. 
VIH y políticas preventivas en Chile. La importancia de la enunciación en la intervención desde Trabajo Social /Vilches

Cordero-Ramos, N. (2011). Trabajo Social y Hermenéutica Crítica: una opción metodológica para desvelar elementos éticos en los orígenes de la profesión en Sevilla. Portularia, 11(1).

Fernández, S. P. (1997). Habermas y la Teoría Crítica de la Sociedad. Legado y diferencias en teoría de la comunicación. Cinta de Moebio, (1), 27-41.

Honneth, A. (2009). Crítica del agravio moral: patologías de la sociedad contemporánea. Buenos Aires: Fondo de Cultura Económica de Argentina.

INDH. (1972). Pacto Internacional de Derechos Económicos Sociales y Culturales (PIDESC). Adoptado y abierto a la firma, ratificación y adhesión por la Asamblea General en su resolución 2200 A (XXI), de 16 de diciembre de 1966. Entrado en vigor el 3 de enero de 1976.

Matus, T. (2003). La intervención social como gramática. Revista de trabajo social, 71, 55-71.

Matus, T. (2010). Experiencia y pobreza en el trabajo social: una lectura frankfurteana. O Social em Questão, 24, 19-42.

Matus, T. (2017). Punto de Fuga. Imágenes dialécticas de la crítica en el Trabajo Social Contemporáneo. Tomo 1. Buenos Aires: Editorial Espacio.

Matus, T. (2017). Una crítica travestida para enfrentar el capital, en P. Vidal (Coord.), Las caras del trabajo social contemporáneo. Santiago de Chile: RIL Editores.

Ministerio de Salud. (2017). Informe epidemiológico nacional. Santiago, Chile.

Ministerio de Salud. (2018). Estado de situación del VIH-SIDA y plan de contingencia de abril 2018. Santiago, Chile.

Muñoz, G. \& Pantazis, Ch. (2018). Social exclusion, neoliberalism and resistance: the role of social workers in implementing social policies in Chile. Critical Social Policy, 39(1), 127-146.

Muñoz, G. (2018). Contra la exclusión: Lugar de enunciación e intervención social en la primera línea. Polis (Santiago), 17(49), 259-278. DOI: https://dx.doi.org/10.4067/S071865682018000100259

Muñoz, G. (2018). Epistemologías críticas e intervención social, en M. Flotts y B. Castro (Eds.), Imaginarios de transformación: el trabajo social revisitado (pp. 137-160). Santiago de Chile: RIL Editores.

ONUSIDA. (2007). VIH-SIDA y los derechos humanos. Recuperado en noviembre 20, 2018, de https://www.ohchr.org/sp/issues/ hiv 
Rojas, C. (2018). Afecto y cuidado: pilar de la política social neoliberal. Polis, Revista Latinoamericana, 49, 127-149. 